\title{
Toward a systemic plant physiology
}

\author{
Gustavo M. Souza • Carlos H. B. A. Prado - Rafael V. Ribeiro • \\ João Paulo R. A. D. Barbosa • Antonio Natal Gonçalves • \\ Gustavo Habermann
}

Received: 4 March 2016/Accepted: 24 April 2016/Published online: 11 July 2016

(C) Brazilian Society of Plant Physiology 2016

\begin{abstract}
This manuscript brings a critical reflection on the epistemological foundations of the science of plant physiology. We discuss the limits of the reductionist view of the science, indicating new epistemological possibilities to plant physiology, specially based on General System Theory and Complex System paradigm, and the further implications of this major science to the human future.
\end{abstract}

G. M. Souza ( ()

Departamento de Botânica, Universidade Federal de Pelotas, Pelotas, RS, Brazil

e-mail: gumaia.gms@gmail.com

C. H. B. A. Prado

Departamento de Botânica, Universidade Federal de São

Carlos, São Carlos, SP, Brazil

\section{R. V. Ribeiro}

Instituto de Biologia, Universidade de Campinas,

Campinas, SP, Brazil

\section{J. P. R. A. D. Barbosa}

Departamento de Biologia, Universidade Federal de Lavras, Lavras, MG, Brazil

\author{
A. N. Gonçalves \\ Departamento de Ciências Florestais, Universidade de \\ São Paulo, Piracicaba, SP, Brazil \\ G. Habermann \\ Departamento de Botânica, Universidade Estadual \\ Paulista Júlio de Mesquita Filho, Rio Claro, SP, Brazil
}

Keywords Philosophy of plant physiology $\cdot$ Plant cognition · Plant science - System biology

\section{Introduction}

During the Symposium of Systemic Plant Ecophysiology held in 2014 in Presidente Prudente, SP, Brazil, scientists willing to reflect on the scientific bases of plant physiology (PP) proposed a resumption of the systemic epistemological perspective, first proposed by von Bertalanffy (1968), to rethink the future of PP. The motivation for this reflection is related to the following:

(i) the classic scientific approach, based on analytical reductionist view of nature, is close to the limit of its explicative power to the phenomena manifested by plants in their different spatial and temporal scales;

(ii) despite of a claim for a more integrative approach built under the auspices of "System Biology" based on practices with the suffix "omic" (genomics, proteomics, metabolomics, organomics etc.), its epistemological and empirical foundations do not differ from the classical paradigm.

The supposed "revolution" caused by the advent of molecular biology techniques have enabled a deep analysis of cellular components but is, in fact, a natural 
consequence of evolution (not revolution) of science founded within the precepts of a "mechanical" universe whose sum of the parts result in a whole that represents or is more closed to the reality itself.

What we seek does not deny the current classical approach in science, which has allowed major technological advances. Instead, it overcomes its limits by creating new meanings for the plethora of data that different techniques have produced, and we also raise new and old questions about the reality of the plant's world around us. We seek a vision that re-signifies general patterns of nature and the relationship of plants with the environment, including human beings. We seek a more inclusive and less fragmented way, contributing to a more sustainable world from an environmental, social and economic perspective. Thus, this manifest highlights not just a scientific view, but also a political one, as we believe that science is a social and cultural achievement, closely linked with the history of its time, with a strong influence on the future of both the humanity and the planet as a whole.

We will discuss the foundations of modern science (post scientific revolution) and its limitations in understanding some natural phenomena related to plant physiology. Then, we will present the epistemological and theoretical principles of a systemic science (or systemic paradigm), based on General Systems Theory and their ramifications into the Complex Systems Theory and Self-Organization. As a consequence, a new perspective of plants as self-organizing complex systems will be presented, endowed with cognitive properties. Thus, the basis for the proposal of a systemic approach for plant physiology, with its implications in science itself, scientific education, economy, and the society will be considered.

\section{The foundations of modern science and its limitations}

Because of the huge complexity of Nature, science attempts to build simplified models that allow some understanding of natural phenomena that is compatible with the technological level of data acquisition. The construction of heuristic models enables the simulation and prediction of certain aspects of Nature. The basis of this scientific method was forged by René Descartes (1596-1650), who proposed the analysis or the decomposition of a problem into smaller parts. The parts should be more understandable separately. Once a consistent knowledge of the parts is obtained, an integration of them reaches a synthesis and the initially proposed problem is solved. All this is naturally immersed in a mechanical model of the universe, where the parts are linked in a linear way by causeeffect relationships, and the whole would be the sum of these parts (Mitchell 2009). This general theoretical model of thought and its corresponding scientific method allowed the development of a successful reductionist science, which is founded on the belief that the full understanding of complex phenomena would be embedded in the understanding of its constituent parts, founding the basis of the "omics" science (Sheth and Thaker 2014).

A major problem of this perspective, in addition to the mistake of the scientific model (i.e., the product of objective rationality of the human mind) with the reality itself, is the assumption, even if unaware, of the existence of an implicit determinism in the causal relationships between the objects of a particular system under observation. This belief leads to the certainty of the possibility of natural objects manipulation, modifying them from their components, in order to achieve desired results in a consistent, stable and reproducible way.

However, biological systems are irreducible systems, showing emergent properties that arise from non-linear interactions among their components, which are strongly affected by the surrounding environment (Mazzocchi 2008; Lüttge 2013; Sheth and Thaker 2014; Souza and Lüttge 2015). This was already presented in Aristotle's philosophy by the aphorism "The whole is more than the sum of its parts". Therefore, it would be nearly impossible to reduce the observations made on a particular scale of a system to a lower scale because each particularly scale of a system has its own properties.

Now, a new class of models and epistemology has shown that many fundamental properties of complex systems, especially the biological ones, are emerging properties. Such properties would be, in general, those properties that are observed on a larger scale of the system (high hierarchical level) and that cannot be observed or inferred on smaller scales of the same system (low hierarchical level) (Mitchell 2009; Lüttge 2012; Bertolli et al. 2014). 
Nevertheless, what does "more than the sum of its parts" exactly mean? What kind of effect would cause phenomena attributed to the emergence of nonreducible systemic properties? Supposedly, these properties come from the interactions between different components of the system that alter the simple product of the parts as a linear sum of the particular characteristics of each component. Based on this principle, it must be assumed that the relationships between these components are not linear, so that interactions can generate complex self-organized behavior not directly inferred from specific properties of each component. Therefore, the key aspect in emerging phenomena lies in the interactions between the components of the system, which means that networks really matters (Lucas et al. 2011).

\section{Systemic thinking as the foundation of the science of twenty-first century}

Modern systemic thinking, based on General Systems Theory by von Bertalanffy (1968), created the concept of "organismic" (organismic view of reality) assuming that a living organism is not simply a conglomeration of elements, but a system that has integration and organization. The systemic concept of living beings of von Bertalanffy is supported by the thermodynamics of open systems. Such systems, operating far from thermodynamic equilibrium (point of maximum entropy with maximum disorder), keep their organization from automatous processes (self-organized). Although dependent on inflows of matter and energy from the external environment for their support and development, biological systems are not entities that respond mechanically or are determined by external agents. In fact, in these systems, rather than deterministic cause-effect relationships, the organization is maintained by complex patterns of interactions between parts or sub-systems, categorizing living systems as complex systems (Souza and Buckeridge 2004; Souza and Lüttge 2015).

By complex systems we mean those formed by elements, in general, from many different natures that have relations with each other, among which some ones must be nonlinear, necessarily. The relations of the nonlinear type, often found in natural systems, are commonly relations of feedback (positive ones, amplifying signals, or negative ones, which attenuate signals), giving the system the ability of self-regulation. The set of relations between the elements of the complex system is structured in a network topology type small world and/or free-scale. Small world networks have reduced average distance between elements. Scale-free networks are also small world networks where the distribution of nodes (links) with a number of relationships (connectors) follows a power law. In practical terms, they are networks that present a very small number of densely connected nodes (called hubs, with many relationships with other nodes) and most of nodes have few connections. These types of networks have great efficiency when transmitting information through the system, allowing the establishment of actions between different parts of the network and enabling synchronization and emergent behavior (Mitchell 2009; Barabási 2003; Watts 2003).

In different contexts, these systems have the ability to update themselves through changes in the pattern of connections among the elements, even between different scales (in the case of hierarchical systems), providing a self-(re)organization. Patterns of systemic changes occur depending on the information flow through the system, enabling that, from local signals, the system rearrange certain structures and/or processes or even to reorganize itself as a whole (by non-local interactions) (Csermely 2006; Souza et al. 2009). Reorganization processes can be incorporated with the strengthening of repeated similar experiences and can create stable or recurrent behaviors (habits) from the establishment and maintenance of new connections (Broens and Souza 2014).

Some of the patterns of changes in the complex system networks, also considered as adaptive (GuellMann 1994), are the variations in bonding strength between system elements (connectance). Systems, whose elements are on average more strongly connected, present the ability to perform faster and more accurate adjustments when sensing changes in the external environment. Such capacities provide them greater degree of resistance to change and keeping their organization up to certain limits (homeostasis capacity). Nonetheless, relaxation of the links between elements of a system could provide more flexibility in case of severe disturbances exceeding its homeostatic capacity. This ability can allow higher stability, returning to its undisturbed state following the loss of homeostasis (Souza et al. 2005, 2009). This aspect is directly related to the maintenance and acclimation of plants in changing environments. 


\section{Towards systemic plant physiology: plants as cognitive complex systems}

Starting from a systemic view of nature, several studies have directed attention to the fantastic ability that plants have to interact with all the environmental complexity in their environment. More than simple mechanical responses to external stimuli, the plants are able to deal with environmental adversity in a efficient and self-organized way, showing evidence of cognitive characteristics such as memory, learning, intelligence and communication (Trewavas 2003; Garzón 2007; Thellier and Lüttge 2012; Gagliano 2015).

Often in the environment there is a number of biotic and abiotic stimuli to which the plant is subject daily and throughout its life cycle. The sessile lifestyle of plants promoted an evolutionary path that led them to become modular organisms with minimal specialization of cells and tissues compared to other live beings. Because of sessile and modular nature, the plants shall be able to perceive, interpret and respond to various environmental stimuli efficiently. In order to accomplish such tasks, plants use a system involving a signal transduction network that allows the integration of their modules (Trewavas 2003; Lüttge 2012). Thus, there is need for a very well organized sensing system to provide an efficient exploitation of the environment, responding quickly to potentially damaging circumstances. This perception of the dynamics of plant-environment interaction is the basis of a view of these organisms as sensitive, dynamic and showing highly complex behaviors, searching for resources below and above ground (Brenner et al. 2006; Baluska and Mancuso 2007; Trewavas 2009).

Unlike animals that grow and develop through coordinated changes in a centralized manner, plants grow and develop in terms of what Trewavas (2003) calls "democratic confederations" because there is no a CPU processing information, since the processes related to the growth and development of the plant does not operate on the individual as a whole, but on modules that can in fact be removed while the plant grows (Trewavas 2003). The ability to understand environmental signals is essential for the plant to survive and compete for resources in their natural environment, making them individuals that do not depend on the existence of any specific brain-like tissue to perform operations. Rather, plants have a decentralized cognitive architecture, which is able to interpret and react efficiently to environment challenges (Trewavas 2003; Lüttge 2012).

The acquisition and proper processing of environmental signals are extremely important for plants because this realization leads to choosing the best strategy to ensure the survival and continuity of the species. In addition to realizing the abiotic signs, plants perceive other living beings around them (Mancuso and Viola 2015). The most interesting in relation to this capability is that many plants have abilities to discriminate between their neighbors, and to develop differently in face of other plants, changing their growth behaviors, depending on the genetic relationships with the surrounding plants (Dudley and File 2007), physiological integrity (Gruntman and Novoplansky 2004) and ecotype (Mahall and Callaway 1996; Falik et al. 2006). Therefore, despite the modular nature of the plant bodies, they also have individuality and aspects of consciousness (awareness) (Chamovitz 2012; Marder 2012).

In this context, rather than focusing on the nature of the constitution of the elements of a plant (genetic and biochemical composition), plant physiology should focus efforts on the understanding of the relationships between these constituents, assuming non-linear relationships in a complex network topology. In addition, assuming plants as self-organizing systems, not in thermodynamic equilibrium, plant physiologists cannot ignore the relations with the surrounding environment and its effects in order to propose dynamic models for the understanding of plant systems. Therefore, under a systemic perspective, plant physiology is intertwined and, in fact, is an eco-physiological science (Souza and Lüttge 2015).

It is clear, then, that molecular biology and more recently his sister-Siamese, the "molecular physiology," is only a necessary, but not sufficient, tool for understanding plants, not justifying its prevalence and overlap on other scientific perspectives on botany. Rather, this mainstream has reinforced an extremely positivist and utilitarian view of plants, creating the illusion of control and solution for some critical problems of humanity, such as hunger for example, through manipulation techniques of living matter, when management techniques more simpler and less costly (financially and environmentally) could be deployed. 


\section{The general implications of systemic view in plant physiology}

The current problems faced by humanity are indeed systemic problems, which means they are interconnected and interdependent. The recognition that a deep change of perception is necessary, as well as thinking about the plants and life as a whole to ensure our survival has not yet reached most people, nor the leaders of our corporations, or administrators and professors in our greatest universities. Therefore, this is why it is necessary to bring up this very important subject for all life on Earth.

From the point of view of conservation and food production, the systemic perspective of plants supports the models and techniques for a more sustainable agriculture, inspired by models of organic agriculture, ecological, crop-livestock-forest integration systems, as well as the technical forest restoration based on a greater harmony between the planted species and their environment, inspired by natural models of plant succession.

From the human point of view and society as a whole, the ability to develop greater empathy with plants can inspire a society of greater compassion among human beings themselves, promoting a healthier, fraternal and sustainable relationship for all and to the nature.

However, all these implications will be only possible when this perspective is integrated into the educational system for the training of future scientists in plant physiology. It is a process of training people that must permeate the undergraduate and graduate levels. It is a mindset change process rather than a purely technical and analytical issue. It is an enormous challenge that must be faced by a community of people concerned with the future of science and humanity.

\section{References}

Baluska F, Mancuso S (2007) Plant neurobiology as paradigm shift not only in plant sciences. Plant Sign Behav 2:205-207

Barabási A-L (2003) Linked. Penguin Group, New York

Bertolli SC, Mazzafera P, Souza GM (2014) Why is so difficult to identify a single indicator of water stress in plants? A proposal for a multivariate analysis to access emergent properties. Plant Biol 16:578-585
Brenner ED, Stahlberg R, Mancuso S, Vivanco J, Baluška F, Van Volkenburgh E (2006) Plant neurobiology: an integrated view of plant signaling. Trends Plant Sci 11: 413-419

Broens MC, Souza GM (2014) Sobre uma teoria sistêmica de hábitos. In: Bresciani-Filho E, D'Ottaviano IML, Gonzales MEQ, Pellegrini AM, Andrade RSC (eds) Auto-organização: estudos interdisciplinares, vol 66. Coleção CLE/ UNICAMP, Campinas, pp 273-287

Chamovitz D (2012) What a plant knows: a field guide to the senses. Scientific American/Farrar, Straus and Giroux, New York

Csermely P (2006) Weak links: stabilizers of complex systems: from proteins to social networks. Springer, Berlin

Dudley SA, File AL (2007) Kin recognition in an annual plant. Biol Lett 3:435-438

Falik O, Kroon H, Novoplansky A (2006) Physiologically mediated self/non-self root discrimination in Trifolium repens has mixed effects on plant performance. Plant Sign Behav 1:116-121

Gagliano M (2015) In a green frame of mind: perspectives on the behavioural ecology and cognitive nature of plants. AoB PLANTS 7:plu075. doi:10.1093/aobpla/plu075

Garzón FC (2007) The quest for cognition in plant neurobiology. Plant Sign Behav 2:208-211

Gruntman M, Novoplansky A (2004) Physiologically mediated self/non-self discrimination in roots. PNAS 101:3863-3867

Guell-Mann M (1994) O quark e o jaguar: as aventuras no simples e no complex. Rocco, Rio de Janeiro

Lucas M, Laplaze L, Bennett MJ (2011) Plant systems biology: network matters. Plant Cell Environ 34:535-553

Lüttge U (2012) Modularity and emergence: biology's challenge in understanding life. Plant Biol 14:865-871

Lüttge U (2013) Whole-plant physiology: synergistic emergence rather than modularity. Prog Bot 74:165-190

Mahall BE, Callaway RM (1996) Effects of regional origin and genotype on intraspecific root communication in the desert shrub Ambrosia dumosa (Asteraceae). Am J Bot 83:83-98

Mancuso S, Viola A (2015) Brilliant green: the surprising history and science of plant intelligence. Island Press, London

Marder M (2012) Plant intentionality and the phenomenological framework of plant intelligence. Plant Sign Behav 7:1-8

Mazzocchi F (2008) Complexity in biology. EMBO Rep 9:10-14

Mitchell M (2009) Complexity—a guided tour. Oxford University Press, New York

Sheth BP, Thaker VS (2014) Plant systems biology: insights, advances and challenges. Planta 240:33-54

Souza GM, Buckeridge M (2004) Sistemas complexos: novas formas de ver a Botânica. Rev Bras Bot 27:407-419

Souza GM, Lüttge U (2015) Stability as a phenomenon emergent from plasticity-complexity-diversity in eco-physiology. Prog Bot 76:211-239

Souza GM, Pincus SM, Monteiro JAF (2005) The complexitystability hypothesis in plant gas exchange under water deficit. Braz J Plant Physiol 17:363-373

Souza GM, Ribeiro RV, Prado CHBS, Damineli DSC, Sato AM, Oliveira MS (2009) Using network connectance and autonomy analyses to uncover patterns of photosynthetic responses in tropical woody species. Ecol Complex $6: 15-26$ 
Thellier M, Lüttge U (2012) Plant memory: a tentative model. Plant Biol. doi:10.1111/j.1438-8677.2012.00674.x

Trewavas A (2003) Aspects of plant intelligence. Ann Bot 92:1-20

Trewavas A (2009) What is plant behaviour? Plant Cell Environ 32:606-616
Von Bertalanffy L (1968) General system theory. George Braziller, New York

Watts DJ (2003) Six degrees-the science of a connected age. WW Norton \& Company, New York 